\title{
춘 \\ Produção de conhecimento em Enfermagem: transposição e repercussões no ensino de graduação
}

\author{
Nursing knowledge production: transposition and repercussions on the graduation teaching
}

Producción de conocimiento en Enfermería: transposición y repercusiones en la enseñanza de la graduación

\author{
Wilza Rocha Pereira' \\ ' Universidade Federal de Mato Grosso, Faculdade de Enfermagem, \\ Programa de Pós-Graduação em Enfermagem. Cuiabá-MT, Brasil.
}

Submissão: 03-07-2012 Aprovação: 22-07-2013

\section{RESUMO}

A pesquisa teve o objetivo de analisar a produção de conhecimento em Enfermagem em uma universidade pública, para avaliar o impacto desta produção no ensino de graduação. Realizamos uma pesquisa exploratória e descritiva em duas fases, na primeira fizemos o levantamento dos relatórios de pesquisas executados pelos docentes coordenadores das mesmas, de 2000 a 2009. Tivemos como resultados desta fase o mapeamento dos tipos de estudo realizados, as temáticas e referenciais teóricos e metodológicos mais utilizados. Na segunda fase, estudamos o atual projeto pedagógico do curso de Graduação e cruzamos os dados com o levantamento anteriormente feito, para dimensionar algumas das transposições e aplicações do conhecimento produzido nas pesquisas para o ensino de Graduação em Enfermagem. Concluímos que, de diferentes maneiras, vem ocorrendo não somente a aplicação dos estudos, mas a transposição dos ideais que perpassam os grupos de pesquisa aos quais pertencem os pesquisadores, que conseguiram provocar mudanças na formação em Enfermagem.

Descritores: Enfermagem; Conhecimento; Educação, Ensino.

\section{ABSTRACT}

The research aimed to analyze the production of knowledge in nursing at a public university, in order to evaluate the impact of that production during the Nursing Graduation. An exploratory and descriptive research has been done in two stages. The first one consisted of gathering the reports of researches executed by the teachers who coordinated them from 2000 to 2009 . As a result of this stage, it was mapped the type of studies performed, the themes and the theoretical and methodological references most utilized. During the second stage we studied the current pedagogical project used in the Graduation course, and crossed the data with the previously, to create a dimension to some of the transpositions and applications of the knowledge produced by the researches to the Nursing Graduation course. We concluded that, in different ways, not only the application of the studies has been occurring but also the transposition of ideals that cross through the research groups to which they belong, being able to bring change to nursing education.

Key words: Nursing; Knowledge; Education; Teaching.

\section{RESUMEN}

La investigación objetivó analizar la producción de conocimiento en enfermería en una universidad pública para evaluar el impacto de la misma en la enseñanza del área. Realizamos una pesquisa exploratoria y descriptiva en dos fases. En la primera hicimos un levantamiento de todas las investigaciones de los profesores coordinadores de las mismas, de 2000 a 2009. Tuvimos como resultados de esta fase el diseño de los tipos de estudios realizados, temáticas e referenciales teóricos e metodológicos más utilizados. En la segunda fase, estudiamos el actual proyecto pedagógico del curso de graduación y cruzamos los datos con el levantamiento anteriormente hecho, para dimensionar algunas de las transposiciones y aplicaciones del conocimiento producido en las pesquisas para el enseno de Graduación en Enfermería. Concluimos que, de diferentes maneras, ven ocurriendo nao solamente la aplicación de las investigaciones, más también la transposición de los ideales que de los grupos de pesquisa y de los investigadores, que conseguirán provocar mudanzas en la formación de enfermería.

Palabras clave: Enfermería; Conocimiento; Educación, Enseñanza.

\section{AUTOR CORRESPONDENTE Wilza Rocha Pereira E-mail: wilzarp@gmail.com}




\section{INTRODUÇÃO}

Trata-se de resultado de pesquisa que teve como objetivo analisar a produção de conhecimento em enfermagem em uma universidade pública para avaliar o impacto desta no ensino de graduação. Para tanto realizamos uma pesquisa exploratória e descritiva em duas fases, sendo que na primeira fizemos o levantamento de todos os relatórios de pesquisas coordenados e executados pelas docentes pertencentes ao quadro de professores permanentes do curso de Mestrado em Enfermagem(ME), da Universidade Federal de Mato Grosso (UFMT), no intervalo temporal compreendido entre os anos 2000 a 2009, com o intuito de verificar sobre algumas das repercussões no ensino na área do processo de produzir conhecimento. Foi nosso pressuposto que embora tenha havido um importante incremento na produção científica no local estudado, pouco se conhece sobre como estas pesquisas vem interferindo e quais transformações tem trazido para o ensino de graduação em enfermagem.

Acreditamos que 'a produção de conhecimento qualquer que seja o campo do saber, não pode prescindir do esforço sistemático de inventariar e fazer balanço sobre aquilo que foi produzido em determinado período de tempo e área de abrangência'(1). Entretanto, é importante que um balanço desta natureza nos permita ir além de conhecer e sistematizar o que foi produzido, na direção de ajudar-nos a identificar temáticas e abordagens mais recorrentes, mapear as emergentes, assim como visualizar possíveis lacunas, temas e problemas ainda inexplorados naquela área de estudo, a partir dos quais se possa delinear demandas de novas pesquisas ${ }^{(2)}$. Nessa direção, o interesse por este mapeamento específico, feito na primeira fase da pesquisa, decorreu da necessidade de melhor conhecer, enquanto grupo de pesquisa envolvido com a temática do ensino, as tendências dessa produção institucional para subsidiar reflexões sobre condições necessárias para o fortalecimento do ensino de enfermagem na região.

A pesquisa na área de enfermagem, no Brasil, 'tem progredido tanto em quantidade como em qualidade' mas 'esta explosão da pesquisa está associada à expansão e aperfeiçoamento dos cursos de mestrado e doutorado'(3) e isso se repete, em parte também, no contexto investigado. Da mesma maneira sabe-se que é grande a interferência da criação de um curso no nível stricto sensu no ensino de graduação, uma vez que seus docentes são induzidos de diferentes formas a propor e conduzir novos projetos, nos quais necessariamente precisam incluir os alunos de graduação. Forma-se então um ciclo 'virtuoso' que beneficia, sobretudo, o processo de formação na graduação, uma vez que induz a grande maioria dos graduandos a abrir seus horizontes e a vislumbra-se como futuros mestres e pesquisadores, o que ocorre mais acentuadamente com aqueles que participam da iniciação científica.

Há alguns estudos que afirmam haver poucas mudanças qualitativas nas práticas de cuidar, de gestão ou de educação em saúde e na formação em enfermagem decorrentes das pesquisas e estudos feitos por enfermeiras, a denominada transposição de conhecimentos das pesquisas para as praticas, mas podemos afirmar que são muitos os movimentos que dinamizam o ensino de graduação no local estudado e que grande parte destes são resultado do processo de pesquisar de seus docentes ${ }^{(3)}$. Decorre disso uma de nossas perguntas de pesquisa: como vem ocorrendo a transportabilidade do conhecimento produzido nas pesquisas para o contexto do ensino no curso estudado?

Sabemos que a materialização de resultados e recomendações de pesquisas em novas práticas não ocorre sem direcionamento político-institucional, disponibilidade de recursos e condições de trabalho e sem intencionalidade de pesquisadores/as. Esta é a dimensão política intrínseca ao processo de produção de conhecimento, pois quando tomamos a decisão do que precisamos, podemos e/ou vamos pesquisar, onde, como e com quem faremos isto, estamos definindo alguns 'futuros' e eliminando outros.

Ao escolhermos temáticas e métodos de investigação, tanto quanto as teorias que nos apoiam em nossas análises, estamos fazendo uma escolha que é técnica e também política e, afirmamos, ensinar é uma atividade profundamente política que depende em grande parte dos escopos teóricos com os quais optamos trabalhar nas pesquisas ${ }^{(4)}$. Pensar na produção de conhecimentos implica refletir de onde falamos e como, através do conhecimento que produzimos, podemos interferir de forma cidadã na realidade que nos cerca.

\section{O Contexto do Estudo: A Universidade Federal de Mato Grosso e a Faculdade de Enfermagem}

O contexto deste estudo se constitui dentro da área da saúde em um estado que vem sendo pressionado a aumentar a formação no nível superior em várias áreas, a enfermagem dentre elas. Em Mato Grosso, até o ano 2000, havia dois cursos de enfermagem com a abertura de 160 vagas anuais. De 2000 a 2010 houve um aumento da oferta para 2210 vagas anuais $^{(5)}$, sem, contudo, haver o preparo adequado para a atividade de ensinar, motivo pelo qual iniciaram-se as negociações para a implantação de um mestrado acadêmico em enfermagem na UFMT e também a motivação para ampliar-se a produção científica do grupo de docentes desta instituição federal, condição sine qua non para a aprovação de cursos stricto sensu pela Coordenação de Aperfeiçoamento de Pessoal de Nível Superior (CAPES).

Como pesquisadoras e enfermeiras, falamos como sujeitos que estão profundamente envolvidos nos processos de formação na nossa área em todos os níveis, e embora formássemos no lato sensu ha muitos anos, o stricto sensu era um nível de ensino mais exigente no quesito formação do corpo docente. A Faculdade de Enfermagem (FAEN) investiu por longos anos neste processo e, finalmente, em 2005, tínhamos o mínimo de doutores com produção suficiente e aptos para propor o primeiro mestrado acadêmico em enfermagem de Mato Grosso, que teve seu início no ano de 2006.

A criação do Curso de Mestrado Acadêmico em Enfermagem constituiu um marco para o desenvolvimento da pesquisa na enfermagem mato-grossense, que vem repercutindo em praticamente todos os cursos de graduação na área do estado.

$\mathrm{Na}$ constante busca pela ampliação na qualificação no nível stricto sensu, implantamos, com o apoio financeiro da CAPES e da Fundação de Apoio a Pesquisa de Mato Grosso(FAPEMAT), o Doutorado Interinstitucional em Enfermagem (DINTER) em 
2006, em convênio firmado entre a FAEN e o Departamento de Enfermagem da Universidade Federal de São Paulo, curso este que formou mais seis doutores e somados aos outros nove que já tínhamos no quadro, uma ingressante já titulada, mais oito formados ao longo da década, chegamos em 2010, ao contingente de 23 doutores. Este esforço para a formação de doutores, organização dos grupos e das linhas de pesquisa em enfermagem, resultou em um aumento da produção científica na forma de pesquisa e também no incremento dos níveis de publicação de seus resultados em periódicos melhor avaliados pelo Sistema Qualis/CAPES, com repercussões no ensino de graduação que se refletem no aumento de alunos de iniciação científica e de trabalhos de conclusão de curso ligados aos projetos matriciais de pesquisa dos docentes.

Com a criação do mestrado acadêmico, adentramos no 'campo científico' e estamos vivenciando as suas muitas exigências para que nele possamos permanecer e se legitimar como autoridade científica na nossa área no estado de Mato Grosso ${ }^{(6)}$.

Trabalharemos neste artigo com a noção de campo, entendida ao mesmo tempo com campo de forças e campo de lutas que visam transformar esse campo de forças ${ }^{(7)}$. Desta noção depreende-se a de 'campo científico' com uma luta entre posições adquiridas em lutas anteriores e para a qual impõem-se a exigência de títulos adquiridos em instituições legalmente e tecnicamente preparadas para tal. O campo acadêmico é um lugar de jogo, de uma luta concorrencial onde se disputa o monopólio da autoridade científica, que é quem produz e faz circular o capital científico, mas que só será legitimada após passar pelos rituais específicos do campo ${ }^{(7)}$. Somos um grupo em processo de aprendizado sobre estes rituais que regem o campo científico e sabemos que ainda há muito a aprender neste campo de lutas em que nos inserimos, mas já atentamos para um de seus aspectos, que é a transposição de conhecimentos dos resultados das pesquisas que fazemos em nossos cotidianos de ensinar e de cuidar em enfermagem ${ }^{(6)}$.

Embora saibamos que as pesquisas realizadas repercutam em todos os campos de nossa atuação como grupo de docentes pesquisadoras, iniciamos este estudo para compreender como o vem repercutindo no ensino de graduação da FAEN os primeiros resultados de nosso esforço de pesquisar. São dois os objetivos desta pesquisa, o primeiro será o mapeamento dos projetos de pesquisa que produzimos de 2000 a 2009, com uma sistematização da produção científica em seus aspectos de obtenção ou não de financiamento, agências financiadoras, tipos de estudo, temáticas e referenciais teóricos e metodológicos mais recorrentes; o segundo objetivo será analisar algumas das repercussões do processo de produção de conhecimento no ensino na graduação de enfermagem do local estudado, tendo como uma referência documental o projeto político pedagógico do curso atualmente em execução(8).

\section{MÉTODOS}

Iniciamos o trabalho de coleta de dados levantando, na Pró-Reitoria de Pesquisa (PROPQ) da UFMT, todos os projetos ali registrados entre os anos 2000 a 2009, que foram coordenados pelas docentes do corpo permanente do Curso de
Mestrado em Enfermagem, obtendo um total de 48 projetos. De posse deste material, nós o organizamos segundo os aspectos que nos interessavam pesquisar: projetos financiados e não financiados, agencias financiadoras, principais tipos de estudo, as temáticas e os referenciais teóricos e metodológicos mais recorrentes, bem como a quais grupos e linhas de pesquisa correspondiam, para poder identificar como cada linha e/ou grupo vem impactando no ensino na graduação de enfermagem do local estudado.

Foram nossas fontes de dados: os 48 projetos, devidamente copiados, os currículos Lattes dos docentes para cruzamento e confirmação dos achados dos projetos e também o novo projeto pedagógico do curso de graduação em enfermagem da UFMT.

Os critérios definidos para que a produção das docentes pudesse fazer parte da pesquisa, foram: pertencer ao corpo permanente de docentes do mestrado em enfermagem da FAEN até o ano de 2009; ser coordenadora das pesquisas; e que estas já estivessem concluídas em 2009. Foi excluída a produção de três docentes que entraram no corpo permanente do mestrado em 2010 e aqueles onde a participação se deu apenas como colaboradores das pesquisas realizadas entre os anos de 2000 até 2009. Todas as docentes participaram de vários projetos concomitantemente, mas selecionamos apenas os projetos nas quais estas eram coordenadoras.

O ano de 2000 foi escolhido para o início da coleta de dados por ser o registro mais antigo de docente permanente do mestrado com pesquisa e o de 2009 para fechar o período da coleta por ser o ano em que os registros das pesquisas já constavam como concluídos nos Lattes dos sujeitos da pesquisa. Os aspectos de interesse que analisamos neste estudo foram: a) identificar as temáticas mais frequentemente trabalhadas pelos grupos e linhas de pesquisa; b) identificar quais os referenciais teórico-metodológicos e as técnicas de pesquisa, de coleta e de análise de dados mais utilizadas no intervalo pesquisado; c) identificar quais eram os projetos financiados e não financiados, e quais as principais agências financiadoras dos projetos; d) ressaltar as diferenças na atividade de produção de conhecimento pela enfermagem da UFMT antes e depois do início do curso de mestrado, em 2005; e) conhecer as repercussões da produção de conhecimento nas atividades de ensino da faculdade de enfermagem da UFMT. Para conhecer como este processo vem interferindo no ensino de graduação do curso, consultamos o novo Projeto Político Pedagógico (PPP) do Curso de Graduação em Enfermagem da $\mathrm{FAEN}^{(8)}$ para observar como vem se dando a incorporação dos referenciais teóricos e conhecer quais resultados de pesquisas vem repercutindo mais diretamente no processo de ensino de enfermagem.

Nossa proposta foi responder aos dois objetivos da pesquisa, o primeiro levantar a produção de conhecimento através dos projetos de pesquisa registrados na pró-reitoria de pesquisa da UFMT do grupo e local estudados. Terminada esta primeira fase, partimos para responder nosso segundo objetivo que foi conhecer algumas das repercussões do processo de produção de conhecimento nas atividades de ensino da faculdade de enfermagem da UFMT, tendo por referência o PPP e as ementas das disciplinas do curso onde atuam as docentes 
pesquisadoras que coordenaram projetos de pesquisa no período estudado. Nesta segunda fase fizemos a analise documental do PPP e iniciamos por identificar as disciplinas nas quais atuaram, de forma mais continuada, os coordenadores de algum dos projetos de pesquisa identificados na primeira fase desta pesquisa.

Os Grupos de Pesquisa da FAEN/UFMT responsáveis pela sustentabilidade da produção de conhecimento da graduação e da pós-graduação vêm desenvolvendo estudos com enfoques temáticos e metodológicos diversos na busca da construção de um conhecimento científico que responda às demandas regionais de saúde de forma a promover o desenvolvimento da profissão da enfermagem. Trazemos aqui os grupos ativos na FAEN com suas características principais e ano de criação e os retomaremos posteriormente para analisar como sua produção vem interferindo no ensino de graduação. São eles: a) Grupo de Pesquisa Projeto ARGOS (1996), que hoje se compõe de três subgrupos - grupo de estudos do envelhecimento e da pessoa idosa - GEEPI (2009); Grupo de estudos sobre a saúde da criança e do adolescente - GESCA e o GERAR (2009): que trata dos conhecimentos e práticas em saúde reprodutiva; b) Grupo Enfermagem, Saúde e Cidadania (GPESC), criado no ano 2000, e que vem realizando estudos e pesquisas nas quais são considerados o contexto de vida e saúde no Estado de Mato Grosso, assume que a saúde se faz com respeito a cidadania das pessoas e que a integralidade deve ser o objetivo da atenção a saúde de pessoas, família e comunidades uma vez que todos têm modos próprios de viver e morrer, adoecer e se cuidar, por meio de diferentes sistemas de cuidado com necessidades de saúde também distintas; c) Grupo de Pesquisa em Educação e Formação em Saúde e Enfermagem (GEFOR), formalmente registrado em 2008, desenvolve pesquisas na área de formação e educação em saúde e enfermagem; tem por objetivo desenvolver teorias, práticas, tecnologias e metodologias que norteiem o saber e o fazer em saúde e enfermagem em torno dos fundamentos teórico-filosóficos da educação em saúde e enfermagem, contribuindo com a reflexão e proposição de políticas e práticas de formação e educação em saúde e enfermagem no âmbito regional e nacional. Há, ainda o Núcleo de Estudos em Saúde Mental( NESM), registrado no Grupos Lattes em 2007 que visa desenvolver pesquisas em saúde mental integrando serviços e gestão de saúde mental no SUS e tem como referencial teórico o materialismo histórico-dialético ${ }^{(5)}$.

Seguimos todas as orientações da Resolução no 196/CNS, que trata da pesquisa em saúde, e obtivemos a aprovação desta investigação pelo Comitê de Ética em Pesquisa do HUJM (CEP/HUJM) sob o número 798/2010.

\section{RESULTADOS}

Vimos que as docentes, ligadas aos grupos de pesquisa ou coordenadoras de pesquisas, se envolveram intensamente com o ensino de graduação desde o primeiro semestre do curso, uma mudança importante para criar a identidade com a Enfermagem desde a entrada dos acadêmicos no curso, e que era motivo de reclamações no PPP anterior, em que os alunos só vinham a ter contato com docentes ligados diretamente ao Departamento de Enfermagem no quarto semestre.

Assim tivemos que docentes pertencentes ao GPESC assumiram a quase totalidade das disciplinas do Bloco I, apenas Introdução à Metodologia Científica ficou com uma docente do ARGOS. No segundo e terceiro semestres as disciplinas de Enfermagem e Cidadania II e Teoria do cuidar em enfermagem passaram para a responsabilidade de docentes do GPESC. No Bloco IV, V, VI e VII, quarto semestre até o sétimo, a assunção de disciplinas por docentes ligados aos grupos de pesquisa GEFOR, ARGOS, NESM e GPESC é marcante, sendo que os docentes coordenadores de pesquisa e lideres de grupos de pesquisa, se envolvem em praticamente todas as disciplinas ofertadas pelo curso de graduação em enfermagem, inclusive no Bloco VIII e IX, dois docentes ligados ao ARGOS assumem a coordenação das disciplinas Trabalho de Conclusão de Curso I e, no Bloco IX, Trabalho de Conclusão de Curso II.

Cabe ressaltar que a construção de uma ciência e os processos que a envolvem - assim também é para a Enfermagem - não ocorrem em um cenário neutro, de maneira desarticulada da organização mais geral da sociedade, estando sujeita à disputa de poder, a interesses econômicos e políticos, à compreensão de verdades que definem concepções de ciência e também de currículos e projetos pedagógicos, como poderemos ver mais adiante na discussão ${ }^{(5)}$.

No levantamento feito na primeira fase da investigação, identificamos 48 pesquisas realizadas em todo o período estudado. Destas, 15 (31,2\%) foram realizadas pelos grupos de pesquisa já existentes até o ano de 2004 enquanto que, de 2005 a 2009, tivemos a realização de $33(68,8 \%)$ novas investigações ${ }^{(9)}$.

Do total de 48 projetos, 19 (39,5\%) obtiveram financiamento de órgãos de fomento à pesquisa do tipo definido como auxílio financeiro; e 29 (60,4\%) não receberam financiamento nesta mesma modalidade, ou seja, seus custos foram cobertos pelas próprias pesquisadoras. As principais agências financiadoras das pesquisas do grupo foram a Fundação de Apoio a Pesquisa de Mato Grosso (FAPEMAT), que apoiou 13 (68,4\%) das investigações realizadas; o Conselho Nacional de Pesquisa (CNPq), que financiou cinco (26,3\%); e uma (5,2\%) pesquisa teve o apoio da Organização Mundial da Saúde (OMS). Os grupos de pesquisa que conseguiram obter financiamento para suas pesquisas antes de 2004 foram o GPESC (dois) e o $\operatorname{Argos}(\text { um })^{(9)}$.

O ano de 2005, com a criação do Mestrado, foi um marco para a expansão da pesquisa. Deste ano até 2009, foram propostas 33 novas pesquisas, ou seja, $68,75 \%$ do total das investigações foram realizadas pelo grupo após a criação do Mestrado. Destas 33 pesquisas iniciadas depois de 2005, 16 $(48,4 \%)$ obtiveram financiamento e 17 (51,6\%) não foram financiadas. Podemos então inferir que houve um acréscimo de mais de $100 \%$ (de 15 para 33) no número de pesquisas realizadas e de mais de $500 \%$ (de três, antes de 2005 para 16 depois deste ano) nas que obtiveram financiamento. De 2005 em diante houve uma busca por financiamento por todos os grupos de pesquisa registrados, sendo várias as fontes e havendo desde então um forte apoio da FAPEMAT neste sentido ${ }^{(9)}$.

No intervalo de 2000 a 2009 foram várias as grandes temáticas trabalhadas nos grupos, mas há uma clara concentração nas 
questões que envolvem o trabalho em saúde e enfermagem, temática ligada as linhas de pesquisa dos grupos ARGOS e NESM. Este tema foi estudado em diferentes aspectos, abordando desde suas ferramentas e tecnologias, como os processos de avaliação de serviços, das condições de trabalho e as formas de gestão. Uma segunda temática derivada da anterior foi a do sujeito como trabalhador em saúde. Neste tema, bem menos frequente que o anterior, se discutiu tanto as causas do absenteísmo, como também as repercussões do trabalho sobre a saúde do trabalhador de enfermagem, seus direitos e o exercício de sua cidadania, pesquisas ligados ao GPESC. Há outras temáticas significativas que podem ser identificadas nos estudos do GPESC. Dentre eles temos um estudo sobre demanda judicial na garantia dos direitos à saúde, um sobre morte materna e neonatal, um estudo sobre a morte e o morrer no currículo de enfermagem, todos não financiados. Uma temática relativamente frequente foi a atenção à saúde das pessoas em condições crônicas de saúde, havendo pesquisas que abordaram as necessidades de saúde das pessoas portadoras de diabetes, hipertensão crônica e hipertensão na gravidez e que portavam estomas de diferentes naturezas. Nestes trabalhos é frequente a citação dos familiares como sujeitos do estudo e colaboradores no cuidado a estas pessoas. Dois trabalhos do ARGOS abordaram a questão da adesão e não adesão ao tratamento de algumas doenças como a malária e a tuberculose, endêmicas na nossa região. Os estudos sobre a educação e a formação em enfermagem parecem apontar uma forte tendência e refletem a produção do GEFOR. Desde a sua criação este grupo já teve três projetos financiados e quatro não financiados ${ }^{(9)}$.

Os tipos de estudo predominantes em todos os grupos foram os exploratórios descritivos, os estudos de caso e a pesquisa bibliográfica. Privilegiaram-se, em grande parte dos estudos, as metodologias qualitativas e há dois estudos do ARGOS que fazem referência a utilização das metodologias do tipo quanti-qualitativas. Quanto às técnicas de análise de material de pesquisa foi citada com bastante frequência a análise de conteúdo e ha alguns estudos que utilizaram a análise temática. Dentre as técnicas para coletar dados de pesquisa tivemos uma preponderância em todos os grupos pela escoIha da entrevista em diferentes modalidades: aberta, estruturada, semiestruturada, em profundidade ou do tipo história de vida focal. O questionário também foi utilizado em algumas pesquisas, mas não na mesma frequência das entrevistas. A segunda técnica mais utilizada para a coleta de dados foi a análise documental pelo ARGOS, a terceira foi a entrevista em profundidade, do tipo historia de vida focal, bastante utilizada pelo GPESC e em seguida vieram os grupos focais de discussão, mais comuns no GEFOR ${ }^{(9)}$.

O referencial teórico mais claramente posto nas pesquisas do NESM e ARGOS foi o processo de trabalho na vertente do materialismo histórico-dialético. A análise institucional como perspectiva teórica foi utilizada em quatro pesquisas do GEFOR, que se abre a novas teorias, como a complexidade e o pós-estruturalismo, e através delas vem reafirmando a sua linha principal de pesquisa que é a educação e a formação em enfermagem. A perspectiva conceitual da integralidade em saúde esteve presente em vários trabalhos do GPESC, onde apenas um trabalho refere claramente ter se baseado na perspectiva teórica foucaultiana ${ }^{(9)}$.

\section{DISCUSSÃO}

A modalidade auxílio financeiro, que cobre os custos totais da pesquisa, é a mais interessante para os pesquisadores, mas, na impossibilidade de conseguir este financiamento total, recorreu-se a concessão de bolsas de iniciação científica para alunos de graduação dentro do Programa PIBIC. Aqui se pode observar uma primeira repercussão da produção de conhecimento, que se dá de forma direta, pois os alunos de iniciação científica são graduandos que se iniciam na pesquisa, o que interfere de maneira significativa no seu aprendizado, processo que levou alguns a se identificaram com o mundo da pesquisa e assim que findaram a graduação foram aprovados para o curso de mestrado ${ }^{(10)}$. Outra forma de financiamento foi a busca de bolsas para os alunos de pós-graduação que estavam matriculados no mestrado, o que fortalece a agregação dos mestrandos em torno das pesquisas de seus orientadores.

É importante esclarecer que antes do início do curso de mestrado em enfermagem na FAEN/UFMT, era prática comum que os docentes encaminhassem as suas pesquisas sem qualquer tipo de financiamento e também sem o apoio dos bolsistas, apenas para poder contribuir com a produção de conhecimento que se fazia necessária para atender os critérios que sabiam ser importantes para a criação de um mestrado na faculdade ${ }^{(9)}$.

O processo de obtenção de financiamento e de bolsistas também é regulado pelos rituais do campo científico, que define, através dos pares, quem pode receber financiamento e quase sempre, aqueles que já possuem um capital simbólico acumulado que o legitimam no campo, são os que conseguem apoio financeiro para suas pesquisas ${ }^{(10)}$. Podemos ver claramente a influência de pertencer ao campo científico, ainda que na periferia dele, quando abrimos o curso de mestrado na FAEN, e é norma na UFMT que portadores do título de doutor com pesquisas cadastradas na PROPEQ possam ter até dois bolsistas de iniciação científica e os com titulação de mestre apenas um.

O que parece estar em jogo, nesta procura por financiamento, é 'o monopólio da autoridade científica definida, de maneira inseparável, como capacidade técnica e poder social, ou se quisermos, o monopólio da competência cientifica, compreendida enquanto capacidade de falar e agir legitimamente (isto é, de maneira autorizada e com autoridade) que é socialmente outorgada a um agente determinado'(11). Com o processo de abertura do mestrado houve uma ampliação tanto do quantitativo como na qualidade da produção de conhecimento dos docentes do programa.

Como grupo que reivindica a legitimidade como pesquisadores de enfermagem, nossa capacidade técnica está constantemente sendo questionada, tanto internamente, como externamente. Esse processo pode ser notado pelas grandes temáticas que escolhemos para trabalhar nas nossas pesquisas, que têm sido mais coerentes com as definições vindas dos órgãos de fomento através de seus editais, do que a temas que melhor dominamos.

Há uma aproximação de sentido entre os temas 'trabaIho' e 'práticas profissionais', assim como pudemos ver essa 
convergência entre a 'assistência' e o 'cuidado em enfermagem', não ficando claro nos projetos analisados qual seria a distinção entre tais terminologias. Esta indefinição pode revelar tanto uma escolha intencional ou também uma inconsistência terminológica e, para diferenciar entre uma e outra, é necessário que o pesquisador esclareça, no delineamento de sua pesquisa, qual a acepção foi dada ao termo. Quando não há este esclarecimento no contexto da produção de conhecimento, isto pode ser interpretado como uma fragilidade conceitual nos estudos realizados, penalizando a sua qualidade final e colocando em risco nossas pretensões como 'autoridades científicas' no contexto local ${ }^{(9)}$.

Outro tema bastante recorrente é o da integralidade e da resolutividade no SUS, sendo inclusive identificadas como palavras chave de vários projetos de pesquisa e também nos novos módulos de ensino que foram pensados e fazem parte do novo PP da graduação em enfermagem da UFMT.

No que se refere às repercussões do trabalho de produção de conhecimento no ensino de graduação, podemos dizer que estas são diversas, mas aqui nos interessam aquelas que já podemos ver materializadas no novo projeto pedagógico do curso, aprovado em $2010^{(8)}$. Por exemplo, temos que a temática sobre o trabalho em enfermagem foi estudada em contextos físicos variados e que a expressiva maioria foi realizada dentro do Sistema Único de Saúde (SUS). Nos pressupostos teóricos do novo projeto pedagógico do curso de enfermagem, há uma afirmação neste sentido 'O desenvolvimento de projetos de ensino, que tomam por base a realidade de saúde e o SUS, colabora em muito para a mudança no paradigma de formação dos profissionais de saúde, não só propiciando projetos inovadores como também a incorporação de um conjunto importante de novas referências para a formação em conformidade com os princípios e diretrizes do $\mathrm{SUS}^{\prime(8)}$.

Alguns destes princípios podem ser encontrados nas pesquisas sobre o SUS, que abordam a integralidade e que foram desenvolvidas dentro da estratégia da saúde da família, outros nos centros de atenção psicossocial e alguns, ainda, em residências terapêuticas que recebem os usuários dos SUS/ CAPS. Quantos aos locais de realização dos estudos temos ainda dois que foram feitos em ambiente escolar, com adolescentes. No último contexto, o hospitalar, tivemos pesquisas realizadas em ambulatórios, unidade de terapia intensiva de adultos e também neonatal e em pronto socorro. Encontramos pesquisas desenvolvidas nos três níveis de atenção, o da atenção básica, nível secundário e o terciário, com uma acentuada inclinação para a atenção básica ${ }^{(9)}$.

O cuidado de enfermagem não foi tema principal de pesquisas, mas este perpassou todo o projeto pedagógico da graduação, tanto que seus pressupostos teóricos são assim descritos 'Assumir o cuidado como eixo orientador na formação do enfermeiro requer o reconhecimento de que o cuidado enquanto domínio do núcleo específico da prática da profissão encontra-se numa intersecção com os demais trabalhos em saúde ${ }^{(8)}$.

Pudemos perceber ainda um enfoque mais voltado para o trabalho de profissionais de saúde diversos, alguns se focaram no profissional enfermeiro e uns poucos na equipe de enfermagem. Esta escolha pode indicar um interesse em temas mais genéricos ligados a saúde e ao sistema de saúde, bastante importantes para conhecer este grande universo. Para uma área de conhecimento em construção como a enfermagem, nos fragilizamos como área, pois pouco realimentamos nossos saberes e a ciência da enfermagem. É importante lembrar que todos os profissionais de saúde desenvolvem pesquisas procurando valorizar a especificidade de sua área, o que parece não vir ocorrendo no contexto estudado, aonde a enfermagem vem se diluindo na ampla área da saúde e pouco tem investido na ciência do cuidado humano ${ }^{(8)}$.

São temas que apontam para uma questão ontológica, de olhar sobre nós dentro do mundo do trabalho, como nos movimentamos ali e como isto reflete sobre nós mesmos como sujeitos de uma prática social. Do ponto de vista teleológico, ou seja, olhar para onde incide a nossa ação como enfermeiras, docentes e pesquisadoras, outras temáticas e movimentos emergiram e vem influenciando sobremaneira as disciplinas onde estão inseridos os pesquisadores no ensino de graduação. São elas as temáticas da integralidade, do processo de adoecimento e suas repercussões e vivencias nas famílias, que podem ser encontradas em muitos pontos do novo projeto pedagógico. A família do portador de uma condição crônica bem como o acesso e acolhimento nos serviços de saúde são elementos claramente abordados no processo de pensar o ensino de enfermagem como pode ser visto no novo projeto pedagógico do curso, uma reverberação destes elementos já abordados em várias das investigações realizadas pelo grupo de docentes ${ }^{(8)}$.

Percebe-se ainda a influência exercida pelos líderes e pesquisadores dos diferentes grupos no processo de pensar e executar o planejamento do ensino na graduação de enfermagem. Um movimento no sentido contrário, das praticas de ensino influenciando as temáticas de pesquisa pode ser vista nas investigações do GEFOR, que vem realizando estudos onde o ensino de graduação e as praticas pedagógicas nele desenvolvidas têm sido focos temáticos e também já vem provocando algumas mudanças concretas no curso, com ementários sendo ajustados para atender a necessidade de por em pratica algumas metodologias ativas ${ }^{(8)}$.

Na produção de conhecimento, chama à atenção a capacidade de agregação deste processo. Por exemplo, nas pesquisas sobre a atenção a doenças específicas tivemos uma que abordou as necessidades e o cuidado em saúde dos portadores de defeitos de fechamento do tubo neural, que além de incluir as famílias das crianças, também discutiu através de atividades de extensão a cidadania e os direitos com estes usuários no contexto do SUS, o que repercutiu em melhoria da qualidade de vida das crianças e famílias afetadas. Tivemos ainda dois trabalhos que abordaram algumas das tecnologias utilizadas em enfermagem como o uso do cateter venoso central de inserção periférica no cuidado de enfermagem e também a utilização dos diagnósticos de enfermagem em situações específicas.

Talvez por ser um grupo que apenas há alguns anos vem trabalhando no processo de produzir conhecimentos através de pesquisa, observa-se uma tendência no que se refere ao marco teórico destas: define-se um quadro limitado de conceitos, não necessariamente ligados a uma concepção teórica mais reconhecida e mais estruturada. Este uso de determinados 
conceitos, de maneira às vezes aleatórias e desligados de contextos teóricos maiores, nos parece ser uma das fragilidades das pesquisas realizadas por alguns pesquisadores do grupo, já que o método científico exige que 'o significado das palavras tem que ser claro, preciso e com suas fronteiras bem demarcadas ${ }^{\prime(12)}$. Boa parte dos trabalhos de pesquisa não define um marco teórico preciso, o que dificultou a análise deste quesito e acreditamos que seja um aspecto que talvez necessite de mais discussões no grupo, pois pode representar tanto uma apreensão teórica incipiente acerca do que aproxima e identifica os trabalhos realizados nos grupos e linhas de pesquisa como também pode indicar uma maior flexibilidade para novos referenciais teóricos.

Este grupo atua em uma das instituições encarregadas da produção e circulação dos bens científicos e da formação e circulação dos produtores desses bens. Em decorrência desta inserção, o grupo já possui, para a realidade local, a acumulação de um importante capital simbólico, que vem se construindo através da realização de pesquisas e da formação de mestres, capital este que pode ser colocado em risco quando um ou outro pesquisador não fala a linguagem exigida no seu campo científico. Esta linguagem compõe um importante capital simbólico, que diferencia e distingue o grupo de outros que não pertencem a este campo $^{(7)}$.

O capital simbólico é composto por bens simbólicos, considerados como aqueles mais valorizados por um determinado grupo social ${ }^{(14)}$. Como falamos desde a universidade, de uma atividade humana muito específica, que é a produção de conhecimento, lembramos que a consistência e a coerência teórica no trabalho de pesquisar, fazem parte destes bens simbólicos ${ }^{(14)}$.

A crítica que pode ser feita é que esta apreensão parcial de teorias e conceitos resulta em estudos mais descritivos e menos analíticos, pois é a escolha de uma ou mais teorias que nos permitem subir no patamar reflexivo e produzir análises mais consistentes das realidades pesquisadas. A consequência desta opção é ficar na superficialidade dos dados e não se avançar no conhecimento, mas apenas reproduzi-lo e tratar superficialmente esta questão é um risco que pode levar a desqualificação do grupo que pretende estar dentro do exigente campo científico.

Assim 'o pesquisador deve adquirir um nível amplo e profundo de compreensão do assunto da pesquisa. Deve haver não apenas familiaridade, mas intimidade com o assunto. As relações de causa e efeito devem ser quase sentidas ou intuídas. Não basta ler os livros e artigos sobre a teoria subjacente.
A intimidade é também com o mundo supostamente descrito por esta teoria'(15).

Relembramos que, na atualidade, os resultados são muito exigidos, não importando os processos ${ }^{(14)}$ e estes se dão em 'um mundo altamente competitivo e desigual que é o da produção científica'(16) onde nos situamos, como grupo de pesquisadoras, desde o momento que decidimos dele fazer parte.

Reiteramos que 'não há teoria sem uma prática que a alimente, fortaleça e modifique e que não há prática sem uma teoria que a atravessa e lhe dê sustentação. Tomadas dessa forma, teoria e prática são elementos distintos de um mesmo e indissociável movimento - o de conhecer os mundos em que vivemos e nos quais nos tornamos o que somos ${ }^{\prime(17)}$.

\section{CONSIDERAÇÕES FINAIS}

Neste artigo nos reportamos a um conhecimento ainda em construção e que já vem produzindo importantes modificações nas maneiras de pensar e executar o ensino de graduação em enfermagem. Como pesquisadoras, estamos falando de um lugar e de uma área específica, a enfermagem e em um contexto também restrito, o da produção de conhecimento científico de um grupo de docentes que tem mais de trinta anos de experiência no ensino de graduação, mas apenas oito na pós graduação stricto sensu.

Se ha experiência na graduação é grande o mesmo não podemos falar da pós graduação, nesta o grupo ainda está em processo de aprendizado e aqui há muito a aprender, visto que este nível de ensino é o mais regulado no nosso país, com normas e regras mudando a todo momento. Estamos dentro de uma instituição, a universidade, que não só produz mas faz circular os bens científicos, bem como é responsável pela formação de novos produtores desses bens, os futuros pesquisadores e formadores de profissionais em várias áreas de conhecimento.

Em decorrência desta inserção na universidade e no estado, o grupo já possui, para a realidade local, a acumulação de um importante capital simbólico, que vem se constituindo através das praticas de ensinar e de realizar pesquisas e formar mestres em enfermagem para atuar na região. A sua permanência neste campo depende da sua capacidade de realizar as suas praticas de educar e de pesquisar de maneira articulada e com qualidade sempre crescente, condição essencial para manter-se como autoridade científica na região.

\section{REFERÊNCIAS}

1. Dayrell J, Carrano P. Prefácio. In: Sposito MP. O estado da arte sobre juventude na pós-graduação brasileira: Educação, Ciências Sociais e Serviço social (1999-2006). Vol. 1. Belo Horizonte: Argvmentvm; 2009.

2. Sposito MP. O estado da arte sobre juventude na pós-graduação brasileira: Educação, Ciências Sociais e Serviço social (1999-2006). Vol. 1. Belo Horizonte; Argvmentvm; 2009.
3. Paim L, Trentini M, Silva DGV, Jochen AA. Desafios à pesquisa em enfermagem. Esc Anna Nery Rev Enferm 2010;14(2):386-90.

4. Demo P. Educação e conhecimento: relação necessária, insuficiente e controversa. 3.ed. Petrópolis: Vozes; 2002.

5. Depes VBS. A mobilização do conhecimento científico por egressos de um mestrado em enfermagem sob o olhar 
da Análise Institucional. Cuiabá. Dissertação [Mestrado em Enfermagem] - Faculdade de Enfermagem da UFMT.

6. Pereira WR. A produção de conhecimento em enfermagem em um contexto descentrado e adverso. Cienc enferm [periódico na internet]. 2012 Abr [acesso em 30 abr 2013];18(1):9-16. Disponível em: http://www. scielo.cl/scielo.php?script $=$ sci_arttext\&pid $=$ S0717-95532012000100002\&lng =pt.

7. Bourdieu P. O campo científico. In: Ortiz R. Coleção: Grandes Cientistas Sociais. São Paulo: Ática; 1994.

8. Conselho de Ensino, Pesquisa e Extensão (Brasil). Resolução CONSEPE $n^{\circ}$. 114, de 27 de setembro de 2010. Dispõe sobre Alterações Curriculares no Projeto Político Pedagógico do Curso de Graduação em Enfermagem, Bacharelado, da Faculdade de Enfermagem, do Campus Universitário de Cuiabá, da Universidade Federal de Mato Grosso, criado pela RESOLUÇÃO CD Nº8/1975 [resolução na internet]. Diário Oficial da União [acesso em 30 abr 2011]. Disponível em: http://www.ufmt.br/ ufmt/unidade/index.php/secao/site/2422/PROEG

9. Pereira WR. Produção de conhecimento em enfermagem: os significados, dificuldades, limites e repercussões deste processo no cotidiano de docentes do ensino superior de enfermagem no estado de mato grosso. Cuiabá:
FAPEMAT; 2011.68p. Relatório Final de Pesquisa.

10. Dias CA. A iniciação científica e a formação do mestrando em enfermagem: estudo comparativo a luz da complexidade. Cuiabá. Dissertação [Mestrado em Enfermagem] - Faculdade de Enfermagem da UFMT; 2012

11. Bourdieu P. A economia das trocas simbólicas. 6. ed. São Paulo: Editora Perspectiva; 2009.

12. Almeida MCP, Mishima SM, Pereira MJB, Palha PF, Villa TCS, Fortuna CM, et al . Enfermagem enquanto disciplina: que campo de conhecimento identifica a profissão? Rev Bras Enferm 2009;62(5): 748-752.

13. Minayo MCS. O desafio do conhecimento: pesquisa qualitativa em saúde. 9. Ed. São Paulo: Hucitec; 2006.

14. Bourdieu P. O poder simbólico. 13. ed. Rio de Janeiro: Editora Bertrand; 2010.

15. Castro CM. A prática da pesquisa. 2. Ed. São Paulo: Pearson Prentice Hall; [s.d.].

16. EGRY EY. The tsunami, solidarity and the social construction of knowledge in nursing. Rev Esc Enferm USP 2011;45(4):799-801.

17. Meyer DE. Processos coletivos de produção de conhecimento em saúde: um olhar sobre o exercício de enfermagem no hospital. Rev Bras Enferm 2006;59(1):95-9. 